\title{
SPECIAL ARTICLE APS/SPR Virtual Chat: race, racism, and child health equity in academic pediatrics
}

\author{
Tumaini Rucker Coker ${ }^{1}$, David Keller (D) $^{2}$, Stephanie Davis ${ }^{3}$ and Steven Abman ${ }^{2}$
}

Institutional racism exists within Academic Pediatrics within the United States, and it affects our work as researchers, clinicians, and educators. Confronting institutional racism is a challenging life-long struggle for people of all races, but it should be part of the professional mission of all who work in Pediatrics. Creating a path to health equity for children in the United States will involve failure. We should not be daunted by that prospect.

Pediatric Research (2022) 91:1669-1676; https://doi.org/10.1038/s41390-020-01176-w

Steven Abman (SA): Good afternoon and thank you for joining us for the second webinar of the American Pediatric Society (APS) and Society of Pediatric Research (SPR) Virtual Chat Series on Academic Medicine in Pediatrics. Today's discussion is entitled "Disparities in Child Health Care and Outcomes." We are thrilled that you could join us for this series that addresses critical issues facing academic medicine, which include topics ranging from career development, mentor-mentee relationships, health care delivery, diversity and inclusion and many other topics.

Today's topic is a very important one to the field of academic medicine, as it relates to the central idea that social inequities adversely affect health care training, delivery and outcomes. We are fortunate to have two outstanding leaders in the field for today's chat. The first is Dr. Tumaini Coker, Associate Professor of Pediatrics at the University of Washington. Dr. Coker has already had a career of outstanding achievement, as reflected by numerous awards such as the Nemours Child Health Services Research Award for early career child health researchers, and other awards, such as the AAMC Herbert Nickens Faculty Fellowship. She is well-known for her roles in improving health care delivery, especially to those from economically challenged communities. She currently is the Director of Research at the Center for Diversity and Health Equity at Seattle Children's Hospital.

Our second speaker is Dr. David Keller, Professor of Pediatrics from the University of Colorado and Children's Hospital Colorado. Dr. Keller serves as Vice Chairman of Clinical Strategy and Transformation, and leads research, advocacy and implementation strategies to improve health care delivery, especially as related to disparities, in order to improve child health outcomes.

Before beginning today's discussion, however, we would like to briefly pause and recognize the passing of Representative John Lewis this weekend. John Lewis has had a long and impactful career from his role as a young man during the Civil Rights movement in the early ' $60 \mathrm{~s}$ and continuing through the current Black Lives Matter movement at 80 years of age. Along with his mentor and colleague, Dr. Martin Luther King, John Lewis was a tireless and courageous leader and advocate for civil rights, equity, and social justice, and was known as "the moral conscience" of Congress throughout his long tenure as a representative in Congress. His teachings, exemplary leadership and contributions to the betterment of society reflect the very best of values and principles, and serves as a true role model for all. As pediatricians, especially in our roles as leaders and members of the APS and SPR, John Lewis has been especially inspirational in targeting the adverse effects of racism and social injustice on the health and well-being of our children, their families and communities.

We now turn the platform over to our session moderator, Dr. Stephanie Davis, who will introduce our first speaker and lead the session.

Stephanie Davis (SD): I would like to first echo your comments about diversity, inclusion and equity and the remarkable life of John Lewis. As advocates of child health, the APS and SPR are devoted to our mission of improving the health, well-being, and outcomes of children and families. A key role as advocates is to challenge these inequities. Today, we're excited and honored to have Dr. Coker and Dr. Keller provide their insights and wisdom for this session, entitled, "Disparities in Child Health Care and Outcomes." Please use the interface to submit questions and comments. We will be moderating the discussion session after Dr. Coker and Dr. Keller speak. Our first speaker will be Dr. Keller. Thank you.

David Keller (DK): Thank you very much, Stephanie. I'll share with the audience that I'm a little nervous, being the first speaker, because I'm well aware that equity and issues of race in our society are not just problems for our Black and Brown communities. It's a problem for all of us. Particularly for me, a white American cisgender male, it can be really challenging to walk into this space. I expect I will mess up. I hope for your forgiveness in advance and I hope that we can use this opportunity to consider how we need to think about race and equity in the coming years to fix some of the problems that are inherent in our society. I'm going to do this by telling you some stories from my life. I want to start with my childhood because when I was growing up, as far as

\footnotetext{
${ }^{1}$ Department of Pediatrics, University of Washington and Seattle Children's Hospital, Seattle, WA, USA; ${ }^{2}$ Department of Pediatrics, Children's Hospital Colorado and University of Colorado School of Medicine, Aurora, CO, USA and ${ }^{3}$ Department of Pediatrics, The University of North Carolina at Chapel Hill, Chapel Hill, NC, USA

Correspondence: David Keller (david.keller@childrenscolorado.org)
}

Received: 31 August 2020 Accepted: 3 September 2020

Published online: 25 September 2020 
I could tell, race was not a personal problem. There were very few people of color living in Fairfield, Connecticut, where I was raised. Folks of color lived in Bridgeport, Connecticut, which was the next town over. I was taught to treat everyone with respect. We never used the "N" word. I learned to swim with the Black kids at the Bridgeport YMCA. My mother's family was actually from the South where I heard early on the story of my grandmother, a nurse who lost her job down in South Carolina, when she took a Black woman who was hemorrhaging through the wrong door to the emergency room. So I thought, because we were a good family, these problems were not my problems.

But still, during the 18 years I lived in Fairfield, Connecticut, I never asked the question, "Why do none of the Black kids from Bridgeport swim at the beaches I swim in?"

We had beautiful town beaches and they were right next to Bridgeport. Well, it turns out our town had policies that made it impossible for folks from Bridgeport to park near the beach, and so they couldn't swim at those beaches. I just read about this 3 years ago, and as I'm reading the article, I thought, 'Oh my gosh! I never even thought about that. Why didn't I ask that question when I was growing up?'

Because I didn't.

I went to college at Princeton. At Princeton, we had African Americans in our class. We were proud of the fact that we were trying to diversify, but the African Americans hung out at the Third World Center. It didn't even occur to me to think about why the African Americans were hanging out at the Third World Center. We, the white students, worked with them on a number of issues. Our big political issue at the time was divestiture of the University's stock portfolio from corporations that did business in South Africa. I demonstrated with these folks, we marched and chanted together, but during that whole time, nobody talked about the fact that our most renowned University's past president, Woodrow Wilson, was responsible for purging Blacks from the Federal Service during his presidency, and that he embraced the Lost Cause Narrative, which became part of our history. It never occurred to me, to say, why are People of Color, who are all American citizens, hanging out at something called the Third World Center? Does that mean that we didn't think they were part of us? To this day, I don't know. I never asked the question. Thankfully, the Princeton University of today has acknowledged their legacy and is taking action to become a more diverse and inclusive institution.

I trained at Hopkins-wonderful place. I loved my continuity clinic there, and I embraced my patients who were all from East Baltimore. I saw them in the emergency room on non-clinic days. They all had my home phone number-people thought I was a little odd that way. I even made house calls in East Baltimore. And then, I said to myself, all of my patients are Black. Why is it that all of the residents here are white? How did that happen? I asked the question that time, but I didn't think about the question for very long. I was a resident, and so I sort of puzzled about it a little bit, and then decided that it didn't matter. I have to take care of the people in front of me and that's what I did. Finally, I'd ask that question. Why didn't I persist with it? It's something that's bothered me for a long time.

My first job out of residency was with the National Health Service Corps at Crusader Clinic in Rockford, Illinois. Again, a wonderful place. We did great work. My first CME conference was back in Boston. It was run by Paul Wise. He was looking into the variation in mortality in the city of Boston, by race and geography. I said to myself, "Wow, that sounds easy. Why don't I do that, too?" I started with infant mortality. I went back to Rockford, went down to the County Health Department and asked them for a list of all of the child deaths for the past 5 years. I conducted a study that showed that the Black infant mortality rate in Rockford was three times the rate of the white infant mortality rate. It turned out there was a grant for which the Health Center could apply and leadership used my analysis to support it. We got a lot of money to invest in trying to address the problem. At the time, it didn't occur to me that this had been going on for a long time. Why had nobody noticed this before there was grant money available? Why wasn't it an issue that we were trying to address much, much, much earlier? Why was it only important at that time?

After Rockford, I joined the faculty at the University of Massachusetts. We set up something called the Community Faculty Development Center to teach community faculty how to provide education about primary care in their offices. We supported community faculty from 15 different medical schools around New England and New York quite successfully for many years. Early on, we decided that we needed to also teach these folks how to provide education about cultural competence in community practice. How do we incorporate that into our primary care teaching? I worked with a colleague, a white family medicine doctor, to develop a curriculum that was very well received and pretty successful (we thought). We wrote it up; it got published. We'd been doing that curriculum for about 5 years, when an African American participant came up to us at the end of one of our workshops and said, 'Why don't you have any People of Color in your faculty that are teaching this?' The question hadn't occurred to us. Why hadn't we asked that question before? We were of course mortified, and we sought quickly to try to remedy the situation.

At that point, I started to think that this was not really my struggle. I was so embarrassed by that feedback that I pulled back from thinking about race. I thought, "Maybe I should focus on something else" and so I did. I still knew that race was a big problem in our health care system. It was a big problem in our academic medical centers. It was an issue that needed to be addressed. I just sort of thought it wasn't my problem.

Fast forward to Colorado. Again, another wonderful place. At Children's Hospital Colorado, I know that we want to provide high quality healthcare to everyone. I was actually involved in a recruitment where we were trying to bring in a senior faculty member, a Person of Color, a great fit for the job that we had open. We worked really hard to recruit them to join our faculty. We were very excited at the thought of working with them. And then that person turned us down. We heard feedback that, when they looked around Colorado, they didn't see an African American community here of which they could join. I was really puzzled by that. Denver, Colorado has a long history of a very active Black community, with a vibrant history. In reality, it's a small part of Denver and, about 100 years ago, our State government was dominated by the Klan. Our state is becoming more diverse, but it is a slow process. Why hadn't I noticed that before? I think that's the question.

You may be hearing a theme through all of this, that continually has come up throughout my career. Our collective history of racial oppression and how it impacts outcome is clear if you look for it, but only if you ask the right questions. As a white cis-male, I have often found myself not asking the right questions, constantly resolving to do better, and then, once again, being surprised when I get it wrong again. It is really easy to mess up when you walk into this space, and yet it is essential that we keep doing so.

I'm going to close with a story from last year. One of our biggest issues in Colorado is vaccinations. We have the lowest immunization rate of kindergartens in the country. I've been working with the Hospital and with a broad Coalition that's been trying to improve our vaccination rates. It is a tough fight. The anti-vaccine forces in Colorado are quite strong. We supported a bill that we thought would help. I was one of the people testifying at the final hearing in the state legislature. I was surprised when I saw the list of folks testifying against the bill. A well-known, Black poet and performance artist from Denver was testifying eloquently against our bill. He was concerned that increasing requirements at school 
for immunizations would be yet one more tool that would be used as a means of repression against the African American community of Colorado. Initially, I was confused. How can this possibly be? Then I listened a little bit more. His biggest concern was that, if we pass this bill, it would be differentially enforced and become one more way for the system to tell Black parents that they are not doing a good job of raising their children. I was surprised. I was sad. But this time, I listened, and I finally got it. He wasn't saying I was a racist. He was saying we are building systems that could be used to inflict racist outcomes, and we need to think about it that way. I may finally be starting to learn that I need to be humble, and face these truths. I need to listen more and harder and I need to always remind myself that race is always a factor, in the United States.

Last week, our residents (I love our residents), challenged us to think about how we as faculty are going to think about being antiracist. They asked us to put it into a shared document, so we can be accountable for our commitment. In that little box on the screen, I wrote:

"I pledge to apply the lens of racial justice to all of my work in clinic as an educator, and as a leader within our clinical system and profession, to listen humbly to the children, families, and colleagues regarding my privilege and entanglement with systemic racism and to work collaboratively to create systems to do better."

We'll see if I can stick to that.

SD: Thank you, Dr. Keller, for your honesty and wisdom and for telling your personal story about diversity, inclusion and equity. Dr. Coker will now be speaking. We will then move to the discussion part of this webinar.

Tumaini Coker (TC): I hope everyone is having a good afternoonor good evening for those of you on the East Coast. I'm grateful to the APS and SPR for this opportunity to be a guest panelist for this virtual chat, and it's wonderful to be a co-panelist with David. I'm going to take about 15 minutes to talk a little bit about my perspectives and experiences, on dealing with racism within Academic Pediatrics. I hope in the Q\&A we can expand and also talk a little bit more about how we not only work on racism within our own field, but then focus on how to increase equity for our patients and families.

Racism within academic pediatrics is not a new topic for me. It's something that has been present throughout my training and my career. As I prepared to think about what I wanted to share with you for this session, I went back to my files. I found something that I wrote, about this actual topic about 3 years ago, in August of 2017. So I'm going to read that to you and I think that will be a good way to share my perspectives.

In academic pediatrics, diversity is a core value. This is clear from the mission statements, values, goals, and strategic plans of our national organizations, our pediatric societies, and our individual institutions. One clear aim that has been adopted by our organizations and institutions is to increase the representation of underrepresented minorities in academic medicine. We can all agree, I think, that in theory, this is an important goal to achieve. However to achieve it, we must understand why it has been difficult to fully achieve in the past. The "pipeline" is clearly a main factor in the lack of diversity in our field. But, we don't get to diversity and inclusion by moving around the brilliant and excellent faculty of color who are already in academics-by competing to recruit the limited number of Black and Brown faculty who are already in the field. We have to first invest in building a robust and real pathway for Black and Brown students to have a career in academic pediatrics. This will not happen overnight. To have diversity at the academic faculty level, that diversity must exists much earlier in the queue.

But what about the folks already queued up?
Some years ago, I was applying for an NIH Grant, and I was told that I would have a better chance of getting funded, since I'm Black. The faculty member who told me this was an experienced, $\mathrm{NIH}$ funded physician scientist, who recognized the need for greater racial and ethnic diversity in academic medicine. He assumed that the $\mathrm{NIH}$ wanted the same thing. Logically, he figured that some advantage would be given to minority applicants, who had strong NIH grant applications. Sounds reasonable.

However, I've been Black for a long time. I am well aware that in most American institutions, my race, and, for that matter, my gender, is generally not an advantage. Why would the NIH be any different than any of our other institutions? Why would a large academic center be any different, for that matter?

Well, it's not different. In 2011, Donna Ginthner and colleagues, published an article in Science that examined the association between NIH R01 applicants who self-identified their race and ethnicity, with the probability of getting funded. After controlling for the applicant's educational background, country of origin, training, previous research awards, publication record, and employment characteristics, the researchers found that Black applicants were 10 percentage points less likely than white applicants to be funded for that R01. So the evidence suggests that there was actually no advantage for me in my NIH R01 application, but in fact, most likely there was a disadvantage based on the fact that I'm Black.

Understanding this, as well as the other challenges and barriers that underrepresented minority trainees and faculty in academic medicine encounter, is important for a few key reasons. First, to effectively increase the retention of minority faculty in academic pediatrics, we need to understand the challenges that they face in our field. Some of these challenges are systemic racism, such as the NIH example, which has been shown in other studies, as well. Others are the unique, and often frequent experiences encountered by minority trainees and faculty_-defined by the "climate" in academic medicine and our institutions.

Many of these challenges may be best understood by examining the evidence and not simply assuming best intentions within our field. We can examine data such as rates of promotion of faculty by their race and ethnicity. We can also examine the actual experiences that minority faculty have in academic medicine, which we don't do much at all. Understanding those experiences and the overall climate for these faculty is going to require data that are less likely to be available without a targeted effort to collect them through periodic climate surveys, interviews, or focus groups.

If you are faculty member of color, you probably have experienced multiple experiences of racism, some are more frequent, and you may have even accepted them as a fact of life in academics. Others are egregious. And social psychology has provided a term for these experiences that are encountered by minority faculty, as well as women faculty, and likely are invisible to others in academics-microaggressions.

As a Black woman in academics, I lived with microaggressions as a constant companion long before I learned the term. I believe many of these are related to the general stereotypes of Black women in this country. I've heard the word ambitious used probably too many times to be a compliment, and I am often told that I seem "angry" when I have given no indication that I was. There is a subjectivity to these experiences, and it is usually accompanied by some confusion on my part in what the underlying reason for the offense was. When I attended an institutional event for medical school faculty, I walked in with a Latina faculty member. We arrived, walking right behind our white male colleagues, who were a few years older than us. While they were seated for the luncheon, the two of us were escorted to the registration table to help set up and sign in faculty. The assumption, of course, was that we were the administrative staff. There were plenty of apologies when the mistake was discovered, 
but it was not the first time I was assumed to be the administrative assistant for my white male colleagues in academic medicineand it would not be the last either. But each time, I wonder-is that because I am Black? Or because I am female? Or maybe I look too young to be faculty? Regrettably, this last question now is not an option (I have too much gray hair now) — so I am just left with the Black or female options. Perhaps it is because other faculty don't know or recognize me. But how many years do I have to sit at faculty meetings to be recognized that I exist? I know that I stick out like a sore thumb at every faculty meeting (except of course the diversity committee meetings). Am I suffering from the plight described in the Invisible Man, by Ralph Ellison? Sometimes, like him, I feel targeted or invisible.

There are other microaggressions, in which I am not left with the question of why it occurred, because it is obviously related to the fact that I am Black. On one occasion a faculty member rolled his neck and snapped his fingers, and in a stereotypical "Oh, No You Didn't", described how he imagined with glee, that I was going to respond to another colleague in a difficult decision. Of course, this was not even close to my response in real life. This was the imaginary stereotypical Black woman who so often takes my place in meetings or impromptu situations when I am not present, but others imagine what I would have said or how I would have behaved if I were. It is not based on me or my previous behavior, it is based on some imaginary depiction of a stereotypical Black woman with plenty of sassiness and attitude. It's not that I don't have any of that sass or attitude, but it is often overly attributed in greater amounts to me.

I am thankful for the Halloween costume suggestions that hospitals and academic institutions have encouraged over the past few years. When I was in residency, there were no policies or suggestions on acceptable costumes, and I remember one Halloween, when I had to endure hand slaps, high fives, and "Jive Turkey!" from a co-resident in a wig afro with a blacksploitation costume. These types of microaggressions are well-intentioned attempts to relate to me-to connect on a personal level. They are the most difficult to deal with as they come from those for whom I am not invisible, but who don't yet know me as an individual person distinct from a perceived stereotype of who I am expected to be.

So, as you listen to this, if you are white, I hope that you're not trying to remember if you have done any of these things to me or faculty like me. That is not the point.

A close friend and colleague told me years ago about a YouTube that has this clip where he talks about why telling someone that they're racist has to be so stressful. Everybody has biases. And so he has this thing where he says, why can't it just be more like telling someone that they have food stuck between their teeth? Right. In that situation, it's embarrassing, but that person who hears it is thankful. I want to know so that I don't have to walk around with parsley in the middle of my teeth. And so if we can change the way that we take that feedback about racism, and listen, well, that would get us a long way.

Although I wrote this 3 years ago, not much has changed, and the points all remain critically relevant. As I moved from instructor, to assistant and then associate professor, with more and more responsibility and visibility both in my own institution and nationally, these microaggressions have not gone away. They have just changed. I was recently told that my institution would not want to lose me (worry that I would take a position elsewhere), because I am a minority. "You are a minority, so we can't afford to lose you". This cannot be the impression that we give faculty of color-they are not a token, a number, something to show the world how well we are doing in terms of anti-racism, diversity and inclusion. How we treat faculty of color will directly impact our ability to build a robust pathway for students and trainees to become our more diverse academic pediatric faculty of the future.
I get contacted by Black and Brown students all the time, wanting to volunteer in my lab, shadow me in clinic, or just talk with me about my career path. What these students, I believe are also unconsciously trying to ascertain is-what is it like being a Black person in this field? I see how few of you are there-how are you doing? How much do you suffer because of it? Have you survived and thrived? Can I?

When I first started at UW, a young Black graduate student came to me for an informational interview. We had a half hour in my office to talk. And one of the first questions she asked me was "Have you faced racism as a Black woman in academics?" I had never been asked that so directly. And I answered truthfully to her, "Yes, I have."

Our institution of academic pediatrics is like any other institution in this country. Its' structures are built on a foundation of racism. For how many years did APS and SPR deny membership to black pediatricians? We have to stop pretending that we are somehow better than the rest of the country. Yes, police violence and brutality against Black children and adults must end. The justice system has never been just for Black people in this country. Our education system remains segregated, and inequitable in terms of building opportunities for children and preparing them to reach their full potential. Of course, you recognize the gross disparities in health and healthcare that our Black and Brown patients face. But how do we fix the inequities within our own ranks? How can we justify the continued inequities for Black and Brown faculty?

As I now think about that question from that graduate student "Have you faced racism as a Black woman in academics?"-I realize something more. I started my first faculty position in 2007. In my nearly 15 years in academic pediatrics, no non-Black or Brown person has ever asked me that before. Not my supervisors, not my chief, not my advisors, nor my colleagues. We don't talk about our own racism. And if we don't talk about it, we can't fix it. So, I'll leave it there, and I hope that we can have a robust question and answer session.

SD: Dr. Coker, that was really fantastic and thank you for your honesty and transparency. I am going to start with the first question. Could you comment on how COVID-19 has illuminated health care disparities in the United States?

TC: The disparities that we are seeing already existed. For so many people, it was not a surprise that the pandemic was going to hit Black, Brown, and indigenous communities the worst, because of the structures of racism that already exist. The disparities reflect both the direct impact of the COVID-19 infection, and the indirect impacts as well-including everything else that we're going to see well beyond when the vaccine is widely available and used. I think that's the impact that is going to last for so long. We started preCOVID with these wide disparities and it is heartbreaking to know that those are just going to be so much wider when we get to the other side of this.

DK To me, this has been an incredible example of what social capital means and what it means to have accumulated capital, because the folks who are doing OK through COVID by and large, are the ones who have capital, accumulated over generations. They have places they can go. They have houses that have yards.

I took care of a family the other day, a family of color that had a mother and four kids, ages 10 to 15 . They are living in three rooms and they have no place outside of that to go. I'm trying to imagine what it would be like to have those kids all trying to home-school. They said that they have two screens that could be used at any given time. They're living a very different COVID experience than am I. I think that's occurring with many of our patients. The difference in capital assets and the difference in social capital is what's really making a difference.

The families I see that are doing well are the ones where there is support. They've been not only hunkering down, but they have family and friends helping each other out. They are using social 
capital even when they don't have financial capital to get through this. It is fascinating to see those theoretical distinctions acting out in real time. It begs the question, "How do we as clinicians promote social capital? What do we do to help people accumulate the financial capital that they need to be able to survive this?" And that's going to be an ongoing question for us, I think, as we move forward.

TC: I think there's one other piece to it-it's interesting that the murder of George Floyd created at the same time, with COVID, this national focus on racism and how tightly linked all the problems from COVID are with racism. So, the timing is interesting. I think, people are able now to see, what is happening in COVID through the lens of systemic racism and that there's a reason why we're seeing what we're seeing in terms of the disparities.

SD: The next question is specifically for Dr. Coker. In at least one study that examined the disadvantage in $\mathrm{NIH}$ funding described by Dr. Coker, the investigators reported that up to $20 \%$ of that finding to be due to the topics that Black and Brown investigators tend to propose to study such as more community engagement research. How can the APS and SPR work with the NIH and NICHD to encourage the proper attention to these types of disadvantaged areas of research?'

TC: That study was published after the 2011 study. I think that study is fascinating because it breaks down the reasons even more. I struggle with this a little bit. Because, at our institution, we have started, a paid summer program for underrepresented minority students to come and work in a lab. I was thinking about the findings from that article, in the back of my mind, as we brought these students into the labs. I think the kind of research that I do, which is focused on community engaged research and on child health equity, is great. So I want everybody to do that. When I see our students, I want them to love the work that we do in our lab. But then on the other hand, I know that they are going to be facing disparities because they are Black, and then on top of that even more, because they're focused on community engaged research or child health equity research. Of course those are areas with less funding. Does that mean that I need to push people into basic sciences and away from this type of research? No, I still think we should do what we're passionate about, and I think that's what makes a great career. I think we should recognize the reality for Black applicants. What can the NIH and NICHD do to change that? I think the funding priorities need to change-to recognize the importance of community-engagement and health equity research-and then ensure that the funding reflects that as a priority as well.

Then, I think there needs to also be a recognition that to really be able to improve the disparities in care that we see, we really do need to create interventions that work for the communities that are facing the inequities. I work on delivery of care research for well child care services. The interventions in my research are designed, implemented and tested in clinical settings where there are large numbers of underserved children and families. However, if I didn't do that, and designed and developed interventions in the most advantaged populations instead, and then later on said, OK, now I'm going to translate it into Spanish and then make it work for FQHCs and such-well, now that intervention is not going to work as well in that population. So, for an intervention to work, it must be intentionally designed to narrow the disparity. That intervention has to work better in the population that is the most disparate-the one facing the inequity. This means the intervention has to be designed in that population. Most clinicians in practice don't have the capacity to conduct this research, which means really just time, to do that kind of development, and trial work. Given this, this type of research is going to rely on funding and researchers to be able to do it. If we can't get the funding to do it, then we're not going to narrow our disparities.

DK: Building on that point, that's a really good way to think about it. I think we also need to advocate for some changes in the review process, which will be challenging, because we have in our heads this sort of mythic view that the reviews are objective and they're based on scientific fact. Of course, they're based on the biases that we all bring to our review of everything. So I think opening up the review process to include people who are not only perhaps experts in the bench research areas that are related to these topics, but consider having some folks from diverse academic backgrounds, who might have a different lens, who might be able to apply a different lens to thinking about what is an important question. I've served on some panels within HRSA, that have been incredibly multi-disciplinary. While we were judging grant proposals for new clinical systems, the people reviewing had not worked in clinical systems. The perspective of an anthropologist or a sociologist or other folks who are examining the problems we're dealing with, evaluate these issues with a different lens and really helped us see that some of the questions that I might not think are the most important, actually, had relevance outside of my sort of narrow scope of thinking. I think that's the challenge for the $\mathrm{NIH}$; we do want expertise. We want people reviewing who are experts in the respective science, but we also need a breadth of experience and a breadth of perspectives to be able to recognize that there are important questions that may not be inside your more narrow area of expertise.

SD: Thank you for your detailed and thoughtful answers. How can we, as pediatricians, partner with the educational system to rectify the gross inequities in our system?

TC: So I've thought about this a lot through the lens of attention deficit and hyperactivity disorder (ADHD), and in particular, the inequities that exist for Black children with ADHD symptoms and behaviors, compared with white children, in both the healthcare and educational systems. There is a different interpretation of behaviors that are considered problematic at schools, in a Black child compared with a white child. The numbers are astounding regarding the disparities of the use of harsh discipline, like out of school suspensions and expulsions for problematic behaviors among Black girls compared to white girls and Black boys compared to white boys. For Black girls, they are six times more likely to receive harsh disciplinary action at school compared to white girls. Black boys have suspension rates three times higher compared to white boys. I study mental health disparities, and we have disparities both in the recognition of ADHD, for Black children in particular, as well as treatment of ADHD. It's all compounded within school.

So, when there is a Black child who has untreated ADHD, unfair interpretation of their problematic behaviors in school can put them at higher risk for harsh discipline in school and worse educational outcomes. Expulsion, drop out, and even contact with the juvenile justice system may occur. There have been studies that use secondary data to look at this through the school system to prison pipeline. So, what we do as pediatricians, makes a difference. If this kind of problematic behavior that is common with ADHD, goes untreated and unchecked, it leads to school suspensions, expulsions, and we know that kids who are suspended or expelled in high school are more than twice as likely to drop out and not finish, and may have contact with the justice system. This highlights the school to prison pipeline. We have a role in that, I believe, as pediatricians. I think, you know, it's a big topic, but we should think about this, as pediatricians, and treat those kids, like they are ours.

So, one day, as an attending, I was working with the resident in a continuity clinic. It was early in my career and the resident was presenting a patient to me. A middle schooler was being seen for a well child visit. I asked "what kind of grades is he getting"? And the resident replied, "Oh, you know, he is doing fine-he gets mostly Cs." I said it doesn't sound fine. What's going on with this child at school? The resident said, "Well, I think the parent seems happy with it." This was a Latinx family. I said, "do the parents say 
that they seem happy with it?" No, they did not say that. You know, we can't expect less of our Latinx and Black children because the pediatrician cannot relate to them. So, I just think, integrating education into our primary care clinic, is also really important in all of this.

I would love to see universal parental training in primary care. It would be nice to be able to have that kind of time in primary care. I could talk for hours about well-child care and the things that we need to be able to do, and the team that it takes to really provide quality well child care to children. Part of that team is someone who can interface with the school and the teachers, and make sure that the behaviors at home and at school are conducive to that child being successful in school. So, I think there's a lot to that particular question, and I'll just leave it there.

DK: Yeah. I absolutely echo everything that Tumaini just said. I think that it starts with us believing in the potential of our patients. I start asking, and I teach my residents and students to start asking, in kindergarten and first grade, what do you want to be when you grow up? It's my absolute favorite question. Over all, I think that's the critical question that we need to be asking to promote growth, and to nurture hope. I think, as pediatricians, we need to develop relationships over time. Most kids see a teacher for one year. I always went back and visited my old teachers every year when I would I go back to school. I don't hear that from the kids I see in clinic. Because my teachers always seemed to care about what I was doing next. I think many of my patients don't have the sense that there are adults who care what they are doing and where they're going. As pediatricians, we can be that person. We should do that with every visit, whether you are a primary care doctor, an ambulatory specialist, or a neonatologist. We should be paying attention to that trajectory. At the same time, I think there are systemic ways that we can build relationships with schools, as Tumaini mentioned. I think having a team that's focused on wellness and development for kids is a great way to do it.

I'm fortunate to have a team like that at Children's Colorado. We do try to reach out to the schools to try to have those relationships. It's hard. Our schedules don't work like theirs. We're not always able to have the kind of relationship we need to be able to help the child move forward. When I was in a small town practice, in Massachusetts, I knew the teachers and they knew me. I took care of their kids and I could call on them when their students were having troubles. I used to go over to the school and join the Individual Education Planning sessions- that experience was tremendously formative. We have tried for a long time to have our residents do that with their continuity patients, to help them see the connection between what they're seeing in the clinic and what's happening in school. However, most of the time, we have not succeeded. We need to build systems that allow us to have that kind of connection going forward.

Finally, I think our institutions need more formal relationships with school systems. We've been doing a lot of work with asthma in Colorado, where we work with kids in certain school districts that have high rates of asthma and high rates of hospitalization from asthma. There is a joint plan between our asthma specialists, our teachers, the kids, and the school nurses. That's been pretty successful, but it's expensive and hard to do. I think it comes down to thinking about it at all those levels; the individual, the community and the institution. At the bare minimum, we can always ask, "What do you want to be when you grow up?"

SD: We absolutely need to improve our relationship with the school systems. Let's move to the next comment and questions. The disparities are real. The critical question is, where do we go from here? Are we identifying, tracking, and rewarding those people who sponsor, mentor, and shepherd underrepresented minority faculty? Lip-service is insufficient. I am a faculty member who works to get women and underrepresented minorities on projects and published. The only time this was recognized, was by asking me to serve without providing protected time on institutional grants to mentor underrepresented minorities.

DK: I wish I could say that was a unique problem, but it's not. This is one of those places where the institutional momentum is going to keep us from making progress. There are many things our academic institutions asked us to do without compensation. If we really want to move the needle in this direction, we're going to have to rethink our current approach. Addressing institutional racism is something that takes real time. We're going to have to devote time and energy to it, which means we're going to have to prioritize it over something else. Given the way budgets are going right now, we're in a unique time period. Even so, within our institutions, there is a lot of pressure to do something. We're all trying to make the case for how much support is needed, and we need to also figure out how can we redirect resources to be able to support this important work. Will it ever be enough? Probably not. But l'd like to think that we're going to be able to do better, at least in the short term. The tricky part is going to be, how do we maintain that effort when the burning platform of George Floyd's death is no longer pushing us in that direction? That's been the challenge throughout the last 400 years in America.

SD: Thank you Dr. Keller. Our next question: Is it reasonable or insulting to tell an underrepresented faculty recruit that they are needed as a role model?

TC: So, I guess I would want to know what role model and who is the recruit? I think that for a faculty recruit-that is not what they are being recruited for-they are needed as, for example, a physician scientist. Now if that recruit is at the professor level, that's maybe a different story, but not for a junior faculty recruit. I think one of the disservices that we do to young, Black and Brown faculty, is asking them to be everything that's equity, diversity and inclusion.

In the last several weeks, every Black faculty member that I know has been inundated with requests from every group they work with, to be on every anti-racist committee, to look at every statement or asked to help write a statement. It is exhausting. And when it comes time for promotion, I don't think the promotions committee is going to ask how many anti- racism committees we sat on. They want two things from a researcher. They want to know grants. They want to know publications. So, when the criteria for academic promotion changes, then I think, it may be OK to tell the faculty recruit that he or she is needed as a role model. We'd like you to be a role model and mentor the underrepresented minority students, but not unless they're getting FTE for it and they're going to be recognized in the promotions process for this service. We don't want to bring people in and set them up for failure. So, every minute that they're spending on a diversity committee, or on whatever else, to meet the institution's diversity goals, that's a minute that they could be spent getting their $\mathrm{K}$ award, writing a first author manuscript and doing other things that will help them get promoted.

We have to protect our Black and Brown faculty. Because, otherwise, we're just not going to make it. We're going to lose. The pipeline will be cut if you don't allow people to do the work that you want them to do. I feel very strongly about that. I do think that there are going to be faculty that want to do this other very important diversity, equity and inclusion work. I did this as a junior faculty, picked and chose what I wanted to do, knowing that some of the time was going to be taken away from my protected time for productivity. But you do things you're passionate about. However, we can't expect all faculty to do that, and we actually should not ask this of them. I think mentors and advisors can help underrepresented minority faculty the most by protecting them and allowing them to do their scholarship.

DK: I'll put in one more plug. I think you've said it really well. As a researcher, you're evaluated on your papers and grants; that's structural. That's a choice that is made by our academic institutions. Some of us have proposed that there is more to 
academics. In addition to teaching, research and clinical work, there's a fourth dimension to a productive academic life, which involves policy and advocacy. How you build that into a promotion structure within an academic institution is a really interesting question, but I know some people who are trying. In the meantime, if the current structure remains focused only on grants and research, then our job should be to protect junior faculty to be able to write grants and publish research. If we want them to be able to progress as faculty members, and contribute to structural change, then we need to figure out how to reward that work along the path, as well. I think that's a discussion we should be having at a very high level.

SD: I completely concur that we need to evaluate a potential change in our current academic structure surrounding promotion and the metrics we measure. Can you speak to why diversity falls solely on minority faculty? This minority tax is largely a volunteer effort, and doesn't count towards promotion or career advancement, as does participation in other committees.

DK: I think that part of that comes down to what I was talking about in my narrative, when I decided to back out of thinking about culture and race in my teaching. I'd made a mistake; I felt like I had swung and missed. I hate making mistakes because I'm an overachiever and a perfectionist. I think we white folks need to be able to understand that if we get into this work, we're going to make mistakes and that's OK. We shouldn't give up just because we make a big mistake. I think my experience is likely not unique, and it has led to folks saying, 'well, that should be the People of Color who are doing that work, and my job is just to stay out of their way." That's not right. Our job is to recognize mistakes and fix them, not to stay out of the way.

SD: I completely agree. Our next question is 'Have primary care programs with co-located medico-legal partnerships (MLPs), made greater strides around educational disparities? How can we strategically fund these partnerships?'

DK: Well, I'Il always speak up for MLPs, I think they're marvelous. I used to work with one in Massachusetts and we're trying to reinvigorate our program in Colorado. I think it varies a lot between MLPs as to whether they're willing to take on educational issues, depending on the interests of the attorneys that are part of the program. I know that when we started our MLP, the attorneys we were working with did not feel that comfortable with educational law and didn't want to take on some of the education challenges we had. Then we got a new attorney who was comfortable with education law and suddenly we were able to take on educational issues. I've heard that from different programs, the extent to which they are willing to engage with school systems depends on the training and experience of your legal partners.

The big concern that the attorneys have is that educational advocacy takes up a lot of time, because there are so many problems within the system. Often it is easier to pick smaller problems for which they know they can make a difference. So if you're working with a MLP, and you're able to take on educational issues, great! I will tell you, my favorite experience working with the MLP was going to an IEP of a Latinx seventh grader who couldn't read and was getting no services within the school. He wasn't a behavior problem; he just wasn't learning anything. I walked in with the legal aide lawyer and we sat down on either side of the mother. The school system folks walked in, looked at the two of us on either side of the mother and said, "Excuse us for a minute." They walked out and rewrote the IEP they were about to offer. It was rewarding, but I had to ask: "How did this go on for so many years before we were able to fix it?" It's a great tool. Use it if you can, but recognize that those folks are usually running on the edge of resources, and often can't give enough in this area.

SD: The next question focuses on mentoring. The faculty member asking the question is white and has mentored a Black trainee, and said that they could only discuss goals, objectives, how the career was advancing, but could not discuss the elephant in the room surrounding racism. Could you discuss or comment on this? Dr. Keller, that may be a good question for you, given the stories that you highlighted. Dr. Coker, I'd love to hear your comments because I think this is a really important question that leads to struggles for many of us.

DK: Discussing the elephant in the room is scary, especially as a cis-white male older faculty member. I recognize that the power differential between me and my mentee can potentially lead to me causing harm despite all good intentions. I'm thinking of some incidences that I really don't care to share with the large group of people where I've messed up in this realm. So, I fully understand the role of those guardrails. They are in part a way for me to keep from doing harm. I think we would need to have a real high level of trust and a clear understanding of how power works in that relationship to be able to navigate that terrain. I'm not sure I know how to do this well yet. Tumaini, maybe you should talk a little bit.

TC: So, I think it's important to recognize that if you're not used to talking about racism, as a white faculty member, you're going to get it wrong. And that's OK, right? We all have gotten it wrong before, we get it wrong in academics, all of us, in our lives. There is something so difficult about getting it wrong with racism, but we can accept our errors in everything else that we do, including clinical care and talk about them. We can talk about what went wrong in a clinical case. We should be able to talk about what went wrong in a conversation about race with our mentees or our faculty members. I think that's the first part, accepting that we all make mistakes, and that biases are ingrained in us. Our biases are going to come out, as we work in stressful situations. When you're doing something you're not used to, you're not going to get it right. So I think that if, as a mentor, to get to the question regarding whether an African American mentee is facing racism in their work, just ask the question. Like when I told you about the graduate student who asked me, can you tell me in academics, do you face racism as a Black woman? She could have asked me that same question as a white woman or as a white man. It's a valid question because there's racism in the world, and the question is, just tell me about how you have experienced it in academics, and if I personally didn't want to answer, I can say, I don't really feel comfortable talking about that. And that's it, and it's a little bit awkward for both people if I say that, but at least you have asked and open that door. So, when something happens in a year or two, when you start building that relationship, then that person can talk to you. And I think that's a little bit about climate. Things are always going to happen. There will be microaggressions. There are systemic inequities, but as a mentor, I think one of our jobs is giving our mentees the space to talk about it, if they so please.

I think for many young faculty of color and I can speak for myself based on when I started my first faculty position, I never was going to complain about a microaggression at work, to my mentor, or to my division chief, because it was just something that was kind of ingrained in me. Like, oh, you know, just do your work. But then, I was an advisor for our local Student National Medical Association (SNMA) chapter, which is a Black student organization. In working with these medical students, they are so much more intolerant of microaggressions compared to my peers and myself. Things are progressing in a positive way, I think. The younger faculty and trainees, they are pointing out these microaggressions in ways that I did not. They are highlighting these issues so people want to talk about it. They want to be heard. We have to give them the space to do that.

DK: I think the other thing I'd say is that, as an older white, cis, male mentor, I need to be ready to listen and listen. And listen. And not do that thing that I like to do, which is say, "Well, you could do this, or you could do that". If you are going to wade into this area, the first thing you must be ready to do is listen more than you think you need to, before weighing in with sage advice and experience. You are going to hear something that is not in 
your experience. When that happens to me, my instinct is to take it and transpose it into my experience as a young faculty member. As a mentor, I need to make myself resist the urge to do that. I think that's the other reason why it's much easier to just say we're not going to talk about race because, if I mess up, then I am not being helpful and that is always my goal when I'm mentoring.

SD: Thank you! Next question. 'I'd love to hear your thoughts about how we advocate for child health funding that closes disparities. I see challenges with access to mental health, specifically in Oregon, but this is true across the United States. It's definitely a two-tier system. More of my patients, bearing a huge burden of adverse childhood events from systemic racism, have me as their psychiatrist, despite my role as a general pediatrician. This is unsafe and causes huge burnout in primary care. How do we come together in pediatrics to advocate that our specialists are payor agnostic, and that the payment models make sense for kids?

TC: We need a new payment system for health care in this country, to ensure universal coverage for children and adults that includes mental health and dental and everything else in between. We need integrated primary care that doesn't leave out behavioral health services. The payment system is critical to make this happen. If we cannot fix that, we will continue with this two or three-tiered system or more tiers depending on what kind of insurance you have, what state you're in and so forth. This is something that we need to reform on a national level. So, how do we advocate for that? We have to vote and advocate around the need for integrated care with aligned payment systems.

DK: Fifteen or 20 years ago, I recall hearing an interview with the head of the British National Health Service, who was dealing with all of the expenses of the growing elderly population. He was asked, 'Well, what about children?' He replied something like, 'I care deeply about children. I'm going to have to be paying for them 80 years from now and I need to make sure that they age as healthy as possible. That's going to save us money.' We don't have in this country a payment system that looks at the life course in the right way, and that moves us to what we need to do, which is to really capitalize on the fact that investment in early childhood, investment in integrated behavioral health, investment in systems to support children, investment to eliminate child poverty are going to pay dividends for our system, when you get to be my age. We're not set up that way.

There's essentially two ways forward and the debate over which way to do this is going to be an interesting one. One approach is to unify all the systems, create something, so that the people who are paying for care at the end of life care about what happens at the beginning of life. There are several models that do that. The other is to really create a system that focuses on a certain amount of resources and funding for children, especially early in life, separating them out from the rest of the system. A Medicare for Kids with all kinds of things that would make sure that all kids get the sort of great start in life moving forward. I personally think the former system is better, because you're creating a unified system where the people at the end of life care about the people at the dawn of life. I think this will be one of the great policy discussions we are going to have over the next 10 years, as we try to figure out where we want to move with payment reform.

The one thing I do know, is that having a payment system that largely focuses on the management of chronic disease, and the management of the end of life, is not going to get us to support the kind of stuff that we all recognize we need to do for children to be able to set them up to maximize their potential in life.

SD: Thank you for your terrific responses! We are at the end of our session. I do want to highlight one comment from one of the participants before we close. "Part of racism is not seeing the human in front of us, as a unique human being. The structure of academic medicine has historically been ego driven. The elephant in the room is that we need to care more about individuals, underrepresented minorities, included, than our own career. The reason to care is that the human being can teach us something, can help us see the world in a new way, and can add value to this world, if only they are heard, and feel valued."

Unfortunately we were unable to address all questions and comments. This webinar was really enlightening, honest and thought-provoking. I want to thank Dr. Coker and Dr. Keller for your incredible presentations and wise comments. I am now going to turn this over to my colleague, Dr. Abman.

SA: I want to express our thanks to Dr Keller, Dr. Coker and Dr. Davis for this enriching discussion, which exposed the complexity of issues of both disparity and providing effective health care for all children. Finally, we would like to also thank all of our participants for their insightful questions and comments during this "virtual chat."

\section{ACKNOWLEDGEMENTS}

The authors would like to thank the American Pediatric Society and the Society for Pediatric Research for sponsoring the "Virtual Chat" series of webinars, from which this paper is derived. The authors report no external financial support for this work.

\section{AUTHOR CONTRIBUTIONS}

All made substantial contributions to the conception, design, acquisition of data, drafting and revision of the important intellectual content of this article, and have approved of its submission for publication in Pediatric Research.

\section{ADDITIONAL INFORMATION}

Competing interests: The authors declare no competing interests.

Patient consent: Patient consent was not required in the preparation of this paper.

Publisher's note Springer Nature remains neutral with regard to jurisdictional claims in published maps and institutional affiliations. 